\title{
Flight Tracks of Homing Pigeons Measured with GPS
}

Karen von Hünerbein*, Eckhard Rüter ${ }^{+}$and Wolfgang Wiltschko*

\author{
*Zoologisches Institut \\ Siesmayerstr. 70 \\ 60323 Frankfurt \\ Johann-Wolfgang von Goethe University of Frankfurt \\ Phone: +49-69-7982-4719 \\ huenerbein@zoology.uni-frankfurt.de \\ + Rüter EPV Systeme GmbH \\ Lagerstr. 19/10 \\ 32425 Minden \\ Phone: +49-571-646900 \\ mail@tauris.de
}

\begin{abstract}
:
Flight paths of homing pigeons were measured with a newly developed recorder based on GPS. The device consists of a GPS receiver board, a logging facility, an antenna, a power supply, a DC-DC converter and a casing. It has a weight of 33g and works reliably with a sampling rate of $1 / \mathrm{s}$ with an operation time of about $3 \mathrm{~h}$, providing time-indexed data on geographic positions, ground speed and altitude. The data are downloaded when the bird is recaptured. The devices are fixed to the birds with a harness.
\end{abstract}

The measured complete flight paths show many details: e.g. initial loops flown immediately after release and large detours flown by some pigeons. We are here presenting 3 examples of flight paths from a release site $17.3 \mathrm{~km}$ Northeast of the home loft in Frankfurt. Mean speed in flight, duration of breaks and length of the flight path were calculated. The pigeons chose different routes and have different individual tendencies to fly loops over the village close to the release site.

\section{Introduction:}

Homing pigeons are able to home from places where they have never been before and their mechanism of navigation is not yet completely understood $[6,8,10]$.

For this reason, it may be helpful to record the flight paths of homing pigeons, in order to correlate them with physical factors that are assumed to be involved in their navigation and with the topografical structure of the area.

For this purpose we have developed a GPS flight recorder, specifically designed for homing pigeons and to accurately measure flying positions and record their flight paths [2]. 
The technical reason for developing a new type of flight recorder is that the other methods used so far for measuring the flight paths of birds like ARGOS, conventional radio tracking, aircrafts and a magnetic direction recording device have major disadvantages. These are either small range, low resolution in time and space and lack of accuracy or a lot of effort and manpower to carry out measurements or high operation costs. A detailed comparison of different navigation systems can be found in our former publications [2,3].

We are here describing the current, operating version of the GPS flight recorder and 3 flight paths recorded by the device.

\section{GPS flight recorder :}

The conditions for measuring the flight paths of pigeons are: The birds are rather small, 300$500 \mathrm{~g}$, and should not be burdened with more than $10 \%$ of their body weight. Orientation experiments are performed within a medium range of $10-200 \mathrm{~km}$. The pigeons move fast with an average speed of $70 \mathrm{~km} / \mathrm{h}$. They come home within 0.3 - $24 \mathrm{~h}$ after release (= take off). A big advantage of pigeons in contrast to other animals is that they return to their home loft on their own and can easily be recaptured, so that the data can be logged and need not be retransmitted. Pigeons' backs have a free access to the sky as long as they fly. Thus satellites can be received with no obstruction.

Thus the most important requirements of the tracking device are: high accuracy, frequent position fixes, low weight, small size, long range availability of position determination and low impact on the pigeons' behaviour. The most difficult requirement to meet was the low weight. The satellite navigation system GPS (Global Positioning System) was chosen because of its world-wide availability, its high accuracy of position fixes and because the position fixes are independent of one another. GPS accuracy was 300-500 m before May $1^{\text {st }}, 2000$ and is now 30-50 m after the deliberate degradation of the system: the Selective Availability, was switched off. This accuracy is inherent in the system and cannot be changed by a user.

\section{Design of the GPS recorder:}

The GPS recorder (Fig. 1) measures the position of the pigeon during its flight and records these positions in internal memory. The GPS recorder consists of a GPS patch antenna, a hybrid GPS receiver board, a datalogger, a power supply, a DC-DC converter, a connector and a display of status. It has a weight of $33 \mathrm{~g}$ and a physical size of $8.5 * 4 * 1.5 \mathrm{~cm}$. The GPS recorder has a sampling rate of $1 / \mathrm{sec}$ and operates for approximately 3 hours. The time of operation is limited by the capacity of the Lithium battery. The device operates at $3.3 \mathrm{~V}$ and constantly needs $167 \mathrm{~mA}$ power.

At the end of the pigeon's flight the position data are downloaded to a computer. Then the flight paths or parts of it can be calculated or displayed on a map. Data protection in case of power failure is achieved, because the positions are stored on a flash memory. Data can be downloaded as NMEA (standard defined by the National Marine Electronics Association, USA), in a company owned format or as ASCII text. NMEA data are converted by a Visual Basic program to allow processing by standard PC software. 


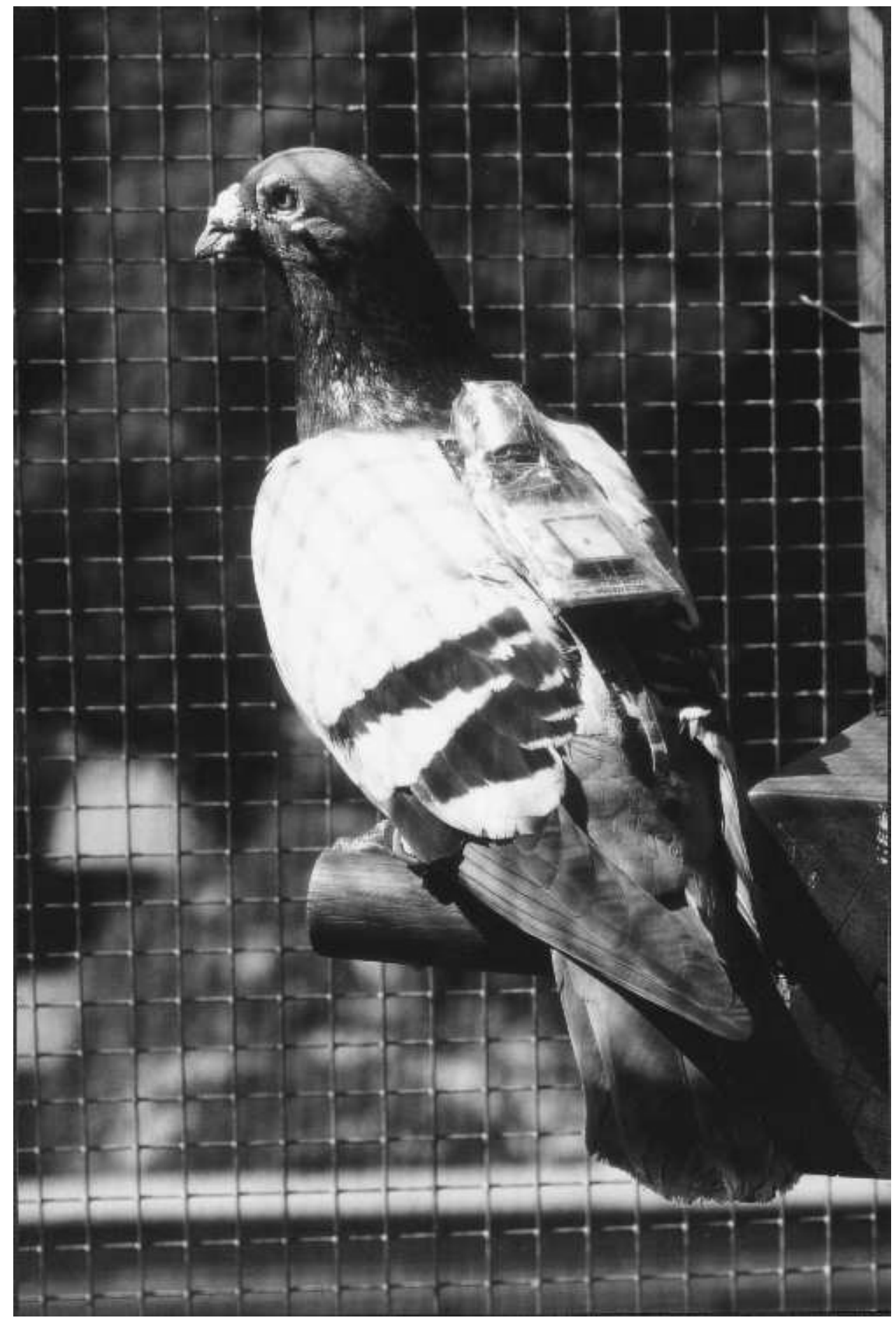

(picture first published in Galileo's World, Summer 2000)

The effectiveness of the device was first demonstrated in a test at the release site Obermörlen [4], where 7 complete and 2 incomplete flight paths could be recorded. Incomplete flight paths were due to long breaks of pigeons exceeding the time of operation of the GPS recorder. 


\section{Discussion of the GPS recorder}

We have now achieved our main aim of developing a GPS recorder sufficiently miniaturized to put it on homing pigeons, have them fly with it and obtain accurately measured flight paths.

The major advantages of the GPS device are the high sampling rate, high number of positions that can be stored and the technology GPS with an accuracy of positions of 10-30 m. These properties lead to a high spatial and temporal resolution of the flight paths.

The two major disadvantages of the device are the weight and the residual magnetic field. The weight is about $10 \%$ of the pigeons' body weight and is likely to cause the pigeons an additional effort in their homing flight. However, in the 3 examples presented in this paper, the homing times of Pigeons A-C were within the range of medians of controls (16-27 min). The residual magnetic field of the device was about 3\% of the earth's magnetic field. Since it has been shown in previous studies that very small diffences in field intensity of about $0.2 \%$ can make a difference in the pigeons' initial orientation [7], this possible influence must be taken into consideration in future studies with the GPS recorder. However in the examples of flight paths shown here the initial orientation does not appear altered compared to previous years (see below).

Another disadvantage of the GPS recorder is the short time of operation of 3 hours which is due to limited battery capacity. This capacity can only be increased by adding a heavier battery or by lowering the sampling rate, which would reduce the temporal resolution. A weight increase is not acceptable, since the present weight already represents a maximum of what the pigeons should carry.

\section{Biological Experiments:}

The flight path described here were produced in spring 2000. We used adult, experienced pigeons. The birds had been trained for 2 months carrying a harness and weights from 8 - 35 g. The pigeons were released from increasing distances and different directions to get used to the equipment. In the experiments we also released control pigeons carrying nothing at all.

Experiments were performed from the release site Büdesheim $17.3 \mathrm{~km}$ North East of Frankfurt (home direction $231^{\circ}$ ) under sunny conditions in a slightly hilly terrain. The skyline of Frankfurt is visible from the ground.

GPS flight recorders were switched on before the test to allow acquisition of satellites before take-off, to acquire a first fix and to check whether the GPS recorder operated. The flight paths consist of 952, 1089 and 1562 recorded positions excluding the periods before take off and after landing. The amount of positions per flight path depends on the pigeon's homing time.

Homing times of GPS pigeons and control pigeons were determined in the traditional way, by a person at the release site and a person at the loft. 


\section{Data Analysis:}

Several software systems were used to measure or calculate different parameters of the flight paths.

TOP 50 a map system containing maps of the area around Frankfurt am Main is capable of displaying GPS data and measuring distances between point on the map. (C) by DASA Aerospace). This system was used to determine the maximum lateral deviation from bee line and the distance from release site at point of maximum lateral deviation

WINTRACK is a software for analysis of tracks of different animals and for displaying tracks ( C by David Wolfer) and was used to determine the length of flight paths from the sum of distances between each pair of position values.

Langrech is a software for calculating values from GPS tracks of homing pigeons ( ( ) by Karen von Hünerbein) and was used to calculate mean speed of flight, time in flight and amount and duration of breaks

\section{Examples of Flight Paths:}

Pigeon A:

Fig 2: $\quad$ flight path of pigeon $A(R S=$ release site, $L=$ Loft $)$

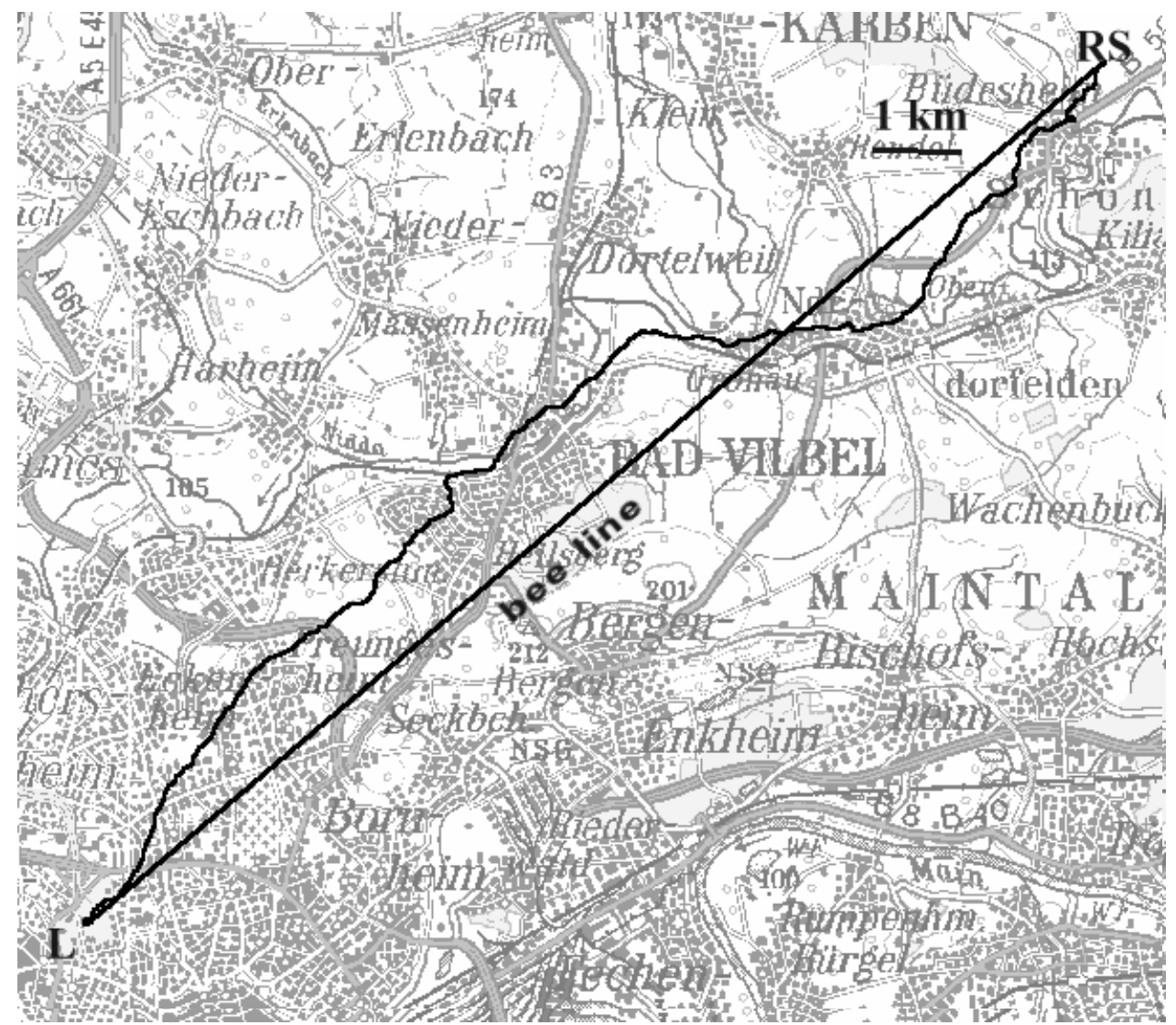

(Map: Copyright (C Bundesamt für Kartografie und Geodäsie,

Frankfurt am Main, 2001. ) 
Pigeon A's flight path is approximately S-shaped, the first part of the flight is located left of the bee line in the direction of flight.

The pigeon flew one small loop over the village of Büdesheim (Fig. 5) and two small loops upon arrival at the loft, there were no loops in the major part of the homing flight after the initial stage. The majority of the flight path is above human settlements. Pigeon A's time of flight was $100 \%$, no time was spent in breaks, homing time was $15 \mathrm{~min}$.

\section{Pigeon B:}

Figure 3: Flight path of pigeon $B(R S=$ release site, $L=L o f t)$

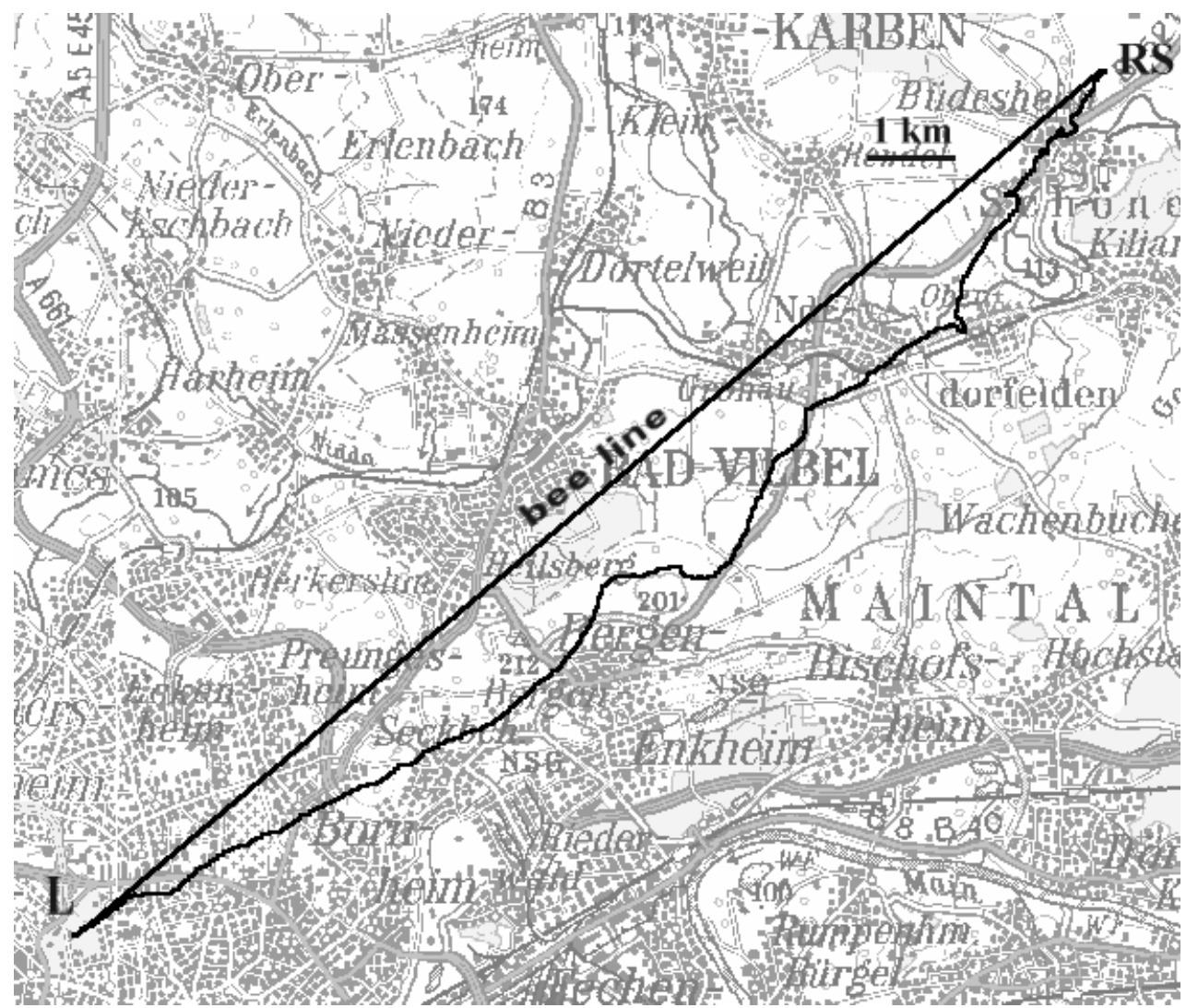

(map copyright (C) Bundesamt für Kartografie und Geodäsie,

Frankfurt am Main, 2001)

Pigeon B's flight path is approximately bow-shaped, the first part of the flight is located left of the bee line in the direction of flight.

Pigeon B flew three small, closed loops (Fig. 5) over the village of Büdesheim, one open loop over Oberdorffelden and no loops in the latter part of the flight. In the middle of the flight it flew parallel to the road B521 for $2.5 \mathrm{~km}$. Then it took a westward turn, possibly to avoid a hill North of Bergen-Enkheim. After the bend around the hill the rest of flight path was directed quite straight towards home.

The length of pigeon B's flight path was $20.3 \mathrm{~km}$ compared to 17.3 of the most direct route. The mean speed was 65.8 km/h. Pigeon B came home within 18 min. 
Time of flight was 100\%, no time was spent in breaks. Compared to pigeon A, the mean speed was lower and the homing time longer, even though the length of flight path was almost identical.

\section{Pigeon C:}

Fig 4: $\quad$ flight path of pigeon $C(R S=$ release site, $L=$ Loft, the most direct route home is the thin straight line)

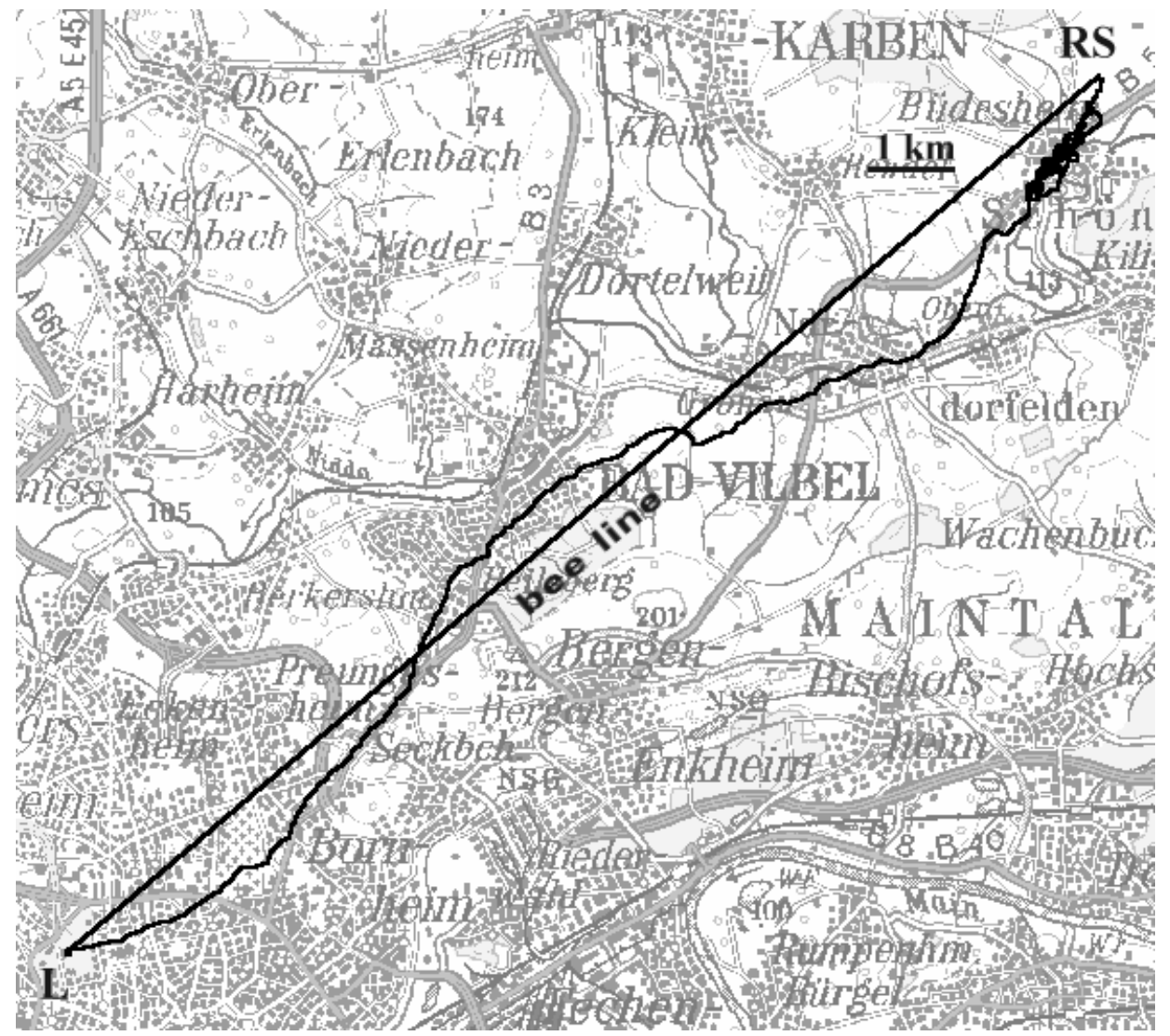

(Map: Copyright (C) Bundesamt für Kartografie und Geodäsie,

Frankfurt am Main, 2001)

Pigeon C's path is approximately 1.5 S-shaped, the first part of the flight is located left of the bee line seen from the release site. The pigeon flew many, extensive loops over Büdesheim (see also Fig: 5) and one small loop upon arrival at the loft, but in the major part of the homing flight there were no loops.

Pigeon C's length of the flight path was $28.4 \mathrm{~km}$ compared to 17.3 of the most direct route. The mean speed was $64.2 \mathrm{~km} / \mathrm{h}$. Pigeon C came home within $26 \mathrm{~min}$. Time of flight was $100 \%$, no time was spent in breaks. Compared to pigeons A and B, the mean speed was lower and the homing time much longer. The length of the flight path was $8 \mathrm{~km}$ longer than the length of the two other pigeons. Since pigeon $C$ made no large detour en route, the increase in the length of flight path must be due to the extensive loops flown over Büdesheim in the initial part of the flight. Since it did not spend time in breaks, much of the increase in homing time must also be due to the loops flown in the first part of the flight. 
The lower mean speed in flight of $64.2 \mathrm{~km} / \mathrm{h}$ compared to $74.9 \mathrm{~km} / \mathrm{h}$ of pigeon A would only account for an increase in homing time of about 3 min assuming the same length of flight path. But it's homing time was 11 minutes longer than the one of pigeon A (Table 1).

Fig 5: Magnification of the first $2 \mathrm{~km}$ of the flight paths:

Loops flown by the 3 different pigeons:

The release site is in the upper right corner of the track. Tracks made visible by WINTRACK [11].

Pigeon A

Pigeon B

Pigeon C

$2.0 \mathrm{~km}(140 \mathrm{pos})$

$2.2 \mathrm{~km}(200 \mathrm{pos})$

$2.1 \mathrm{~km}(700$ pos)

(Distance from upper right corner of track to lower left corner of track)

Table 1: $\quad$ Survey of the data of the three flight paths (* calculated with WINTRACK):

\begin{tabular}{|l|ccc|}
\hline & PIGEON A & PIGEON B & PIGEON C \\
\hline amount of positions/ complete track & 952 & 1089 & 1562 \\
homing time & $15 \mathrm{~min}$ & $18 \mathrm{~min}$ & $26 \mathrm{~min}$ \\
mean speed in flight & $74.9 \mathrm{~km} / \mathrm{h}$ & $65.8 \mathrm{~km} / \mathrm{h}$ & $64.2 \mathrm{~km} / \mathrm{h}$ \\
breaks & 0 & 0 & 0 \\
\hline length of flight path* & $20.4 \mathrm{~km}$ & $20.3 \mathrm{~km}$ & $28.4 \mathrm{~km}$ \\
$\begin{array}{l}\text { shape of flight path } \\
\text { N crossings of the bee line in the } \\
\text { middle of the path }\end{array}$ & $\mathrm{S}$ & bow & $1.5 \mathrm{~S}+$ loops \\
\hline \hline $\begin{array}{l}\text { vanishing bearing } \\
\text { max. lateral deviation from bee line }\end{array}$ & $1.2 \mathrm{~km}$ & 0 & 2 \\
$\begin{array}{l}\text { pigeon's distance from the release } \\
\text { site at point of max. lateral deviation }\end{array}$ & $6.9 \mathrm{~km}$ & $8.1 \mathrm{~km}$ & $3.8 \mathrm{~km}$ \\
\hline
\end{tabular}

The mean homing times of control pigeons ranged from 16 - 27 min. 


\section{Biological Discussion:}

\section{Flight Paths:}

All 3 flight path are similar in the very first part of their flight, pigeons depart about 10-15 ${ }^{\circ}$ counter clockwise of the home direction.

In previous years a release site bias has been observed in Büdesheim that varied between $166^{\circ}$ and $222^{\circ}$ among adult pigeons, it was located to the left of the homing direction as seen from the release site (Fig 6) and [7].

Fig 6: $\quad$ Bias of adult control pigeons at Büdesheim in previous releases:

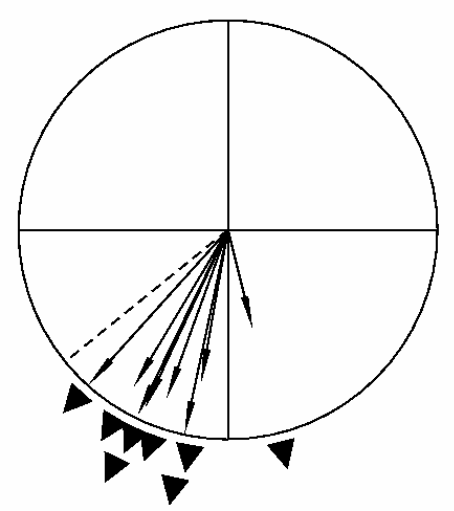

Each arrow represents 1 mean vector of 1 group of adult control pigeons in 1 experiment. The length of the vector represents the scatter, the longer the vector the smaller the scatter. Triangles point in the mean direction of the mean vector. The home direction is indicated by the broken line.

In the years 1981 - 1993 the mean direction of the vanishing bearings was always left of the home direction as seen from the release site.

The deviation to the left in the initial stage of the flight path that can be seen in all 3 pigeons is consistent with the observations of bias in previous years.

In the latter stages of the flight there are individual differences in the route chosen and in the tendency to fly loops. All the flight paths shown here have a rounded, bow or S shape, the pigeons did not fly on straight lines nor on the bee line, even though they stayed quite close to the bee line. Loops are mainly flown over the village Büdesheim closest to the release site in home direction.

The many loops flown by Pigeon $\mathrm{C}$ resulted in a major increase of homing time and an increased length of flight path. Reduced mean speed in flight also caused some increase in homing time. But all three homing times (15, 18 an 26 min) were in the range of the homing times of control pigeons (16-27 min).

\section{Conclusion:}

These results illustrate the potential of the GPS-based technique to yield a wealth of data on the behaviour of animals en route. Our new flight recorder will help to close a gap in biotelemetry, so that now a large number of new species can be tracked over medium distances, if they can be recaptured. 
At present, our GPS recorder is suitable for animals with a weight of above $0.5 \mathrm{~kg}$, but we hope to further decrease the weight in the future. The GPS recorder should find a wide range of application in behavioural and conservational studies.

The 3 flight path shown here are similar to each other in the initial stage, which seems to correspond to the release site bias observed in previous years. Increases in homing times seem to be due to loops flown and a lower mean speed. The homing times of the 3 pigeons carrying GPS are consistent with homing times of the controls.

\section{Acknowledgements:}

This project has been financially supported by the Deutsche Forschungsgemeinschaft DFG (grant to W.W.) and the German Society of Telemetry (Arbeitskreis Telemetrie, grant to K.v.H.). For support of development see [3], especially Stefan Werffeli and Clemens Buergi, ETH Zuerich, Switzerland. For help with experiments: Gisela Schmiedeskamp, Olaf Henseler, Susanne Weber, Bettina Siegmund, Gabriella Götz, Klaus Köhler, Per Stickforth, University of Frankfurt, Germany. For ideas for data analysis: Hajo Hamann, University of Frankfurt, Germany, David Wolfer, University of Zuerich, Switzerland, Kevin Sallee, Ecological Software Solutions, USA.

\section{References:}

[1] DASA AEROSPACE (1998) TOP 50 2.0. Software.

[2] HÜnerbein, K., WiltschKo, W., MÜller, R. And Klauer, B. (1997). A GPS Based Flight Recorder for Homing Pigeons. In: Conference Proceedings of the GNSS 97 (ed.: Deutsche Gesellschaft für Ortung und Navigation) April 21st-25th,1997. Bonn. Volume II: 561-570.

[3] HÜNERBEIN, K. AND MÜLLER, R. (1998). Development of a GPS Flight Recorder for Birds. Arbeitskreis Telemetrie e.V. (ed.) In Conference Proceedings of the European Telemetry Conference 98, Braunschweig: 86-98.

[4] HÜnerbein, K., HAMANN, H.J., RÜTER E. AND WiltschKo, W. (2000) A GPS-based System for Recording the Flight Paths of Birds. Naturwissenschaften 87:278-279.

[5] Kenward, R.E., Pfeffer, R.H., Al-Bowardi, M.A., Fox, N.C., Riddle, K.E., Bragin, Y.A., LEVIN, A.S., WALLS, S.S. \& HodDER, K.H. (in press). New techniques for demographic studies of falcons. Journal of Field Ornithology.

[6] Schmidt-Koenig, K. (1991). Über Karten und Kompasse bei Brieftauben. Verh. Dtsch. Zool. Ges. 84: 125-133 
[7] Wiltschko, W., Nohr, D., Füller, E. and Wiltschko, R. (1986). Pigeon Homing: The Use of Magnetic Information in Position Finding. In: G. Maret, J. Kiepenheuer, N. Boccara (eds.) Biophysical Effects of Steady Magnetic Fields. Proceedings of the Workshop Les Houches France, Springer Verlag, Berlin: 154-162.

[8] WiLtschKo R (1992) Das Verhalten verfrachteter Vögel, Die Vogelwarte 36: 249-310

[9] Wiltschko, R. (1993). Pigeon Homing: Release Site Biases and Their Interpretation. In: Orientation and Navigation - Birds, Humans and other Animals. Proc. Conference Royal Inst. Navigation. Oxford 1993, Paper No. 15.

[10] WiltschKo, W., WiltschKo, R. (1994). Avian orientation: Multiple Sensory Cues and the Advantage of Redundancy. In: Davies MNO and Green PR (eds.) Perception and Motor Control in Birds: 95-119. Springer Verlag, Berlin, Heidelberg.

[11] WOLFER D, (1993-2000) WINTRACK. Software. University Irchel, Zürich, Switzerland. 